\title{
Association between Physical Inactivity and Overnutrition in Adolescent
}

\author{
Idral Purnakarya ${ }^{1}$, Denas Symond ${ }^{1}$, Deane Nabila Putri ${ }^{2}$ \\ \{idral_pkarya@ph.unand.ac.id; idral_pkarya@yahoo.com\} \\ ${ }^{1}$ Department of Nutrition, Faculty of Public Health, Andalas University, 25163, Padang, Indonesia \\ ${ }^{2}$ Undergraduate in Faculty of Public Health, Andalas University, 25163, Padang, Indonesia
}

\begin{abstract}
Adolescent overnutrition is a serious public health problem, with consequences that extend into adulthood. The aim of this study was to know association between physical inactivity and overnutrition in adolescent. An sex matched case control study of adolescent age 15-17 years old in Senior High School Pembangunan in Padang. The case were 40 adolescent overnutrition and the control $(n=40)$ were adolescent without overnutrition recruited from the same school. Physical inactivity collected by using Adolescent Sedentary Actuvity Questionaire. Nutritional status assessed by using anthropometric. Data analysis was done using Mc Nemar test on Epi Info version 7 software. Physical inactivity was associated with overnutrition in adolescent $(\mathrm{OR}=4.2$; 95\% CI: $1.58-11.14 ; \mathrm{p}=0.001)$. The findings of this study have confirmed the association overnutrition with physical inactivity in adolescent. To reduce overnutrition in adolescent should be providing and promoting physical activity in school.
\end{abstract}

Keywords: physical incativity, overnutrition, adolescent, school.

\section{Introduction}

The prevalence of overweight and obesity among children and adolescents aged 5-19 has risen dramatically from just $4 \%$ in 1975 to just over $18 \%$ in 2016 [1]. Overweight and obesity in childhood and adolescents are greater risk of developing noncommunicable diseases such as hypertension, stroke, acute myocardial infarction, heart failure, diabetes mellitus in adulthood [2]. The 2013 Indonesia Basic Health Research shows that the prevalence adolescents overweight and obesity is 10.3 in $13-15$ years old and $7.3 \%$ in $16-18$ years old [3]. Adolescents overweight and obesity is a particular public health concerns for West Sumatra province because who are overweight and obesity have slightly higher than the national prevalence [3].

Over nutrition is caused by multiple factors. There are genetic, eating habits, physical inactivity, environmental, socio-economic and cultural factors $[1,4]$. Physical inactivity is a risk factor for a wide range of health problems. An increase in physical inactivity due to the increasingly sedentary nature of many forms of work, changing modes of transportation, and increasing urbanization [2].

Therefore, the main objective was to know association between physical inactivity and overnutrition in adolescent. 


\section{Method}

A matched case-control study was conducted to 40 adolescents subjects with overnutrition were included in the case group, and 40 adolescents subjects with normal were included in the control group at the Pembangunan Senior High School from April until May 2018 in Padang. Sampling for the case group was using simple random sampling, then the control group using purposive sampling with sex matching. Sex matched cases and controls were recruited on a 1:1 ratio individually. Informed consent was obtained from the adolescents before the data was collected. Data collection was done through questionnaires and direct interviews with respondents. Respondent characteristics such as age and sex were obtained from the subjects during the interview.

Physical inactivity was assessed using the Adolescent Sedentary Activities Questionnaire (ASAQ) which assesses the time spent in a comprehensive range of sedentary activities among adolescents [5]. The sedentary activities identified included watching television/videos/DVDs, computers, e-games and e-communication, study, reading, sitting with friends, telephone use, listening or playing music, motorized travel, hobbies and crafts, all performed out of school hours [5].

Data were analyzed using Epi Info version 7 software (Epi Info ${ }^{\mathrm{TM}}$, Centers for Disease Control and Prevention, Atlanta, USA). Descriptive analysis was carried out to see the distibution of the respondents characteristics. To see an overview of the main characteristics and independent variables, univariate analysis of categorical data was carried out by presenting numbers and percentages. Furthermore, bivariate analysis was performed using the McNemar test to examine the association physical inactivity and overnutrition in adolescent.

\section{Result}

Table 1. shows the general characteristics of the respondents. Most of the case were female and 16 years old. Majority of case $(77.5 \%)$ were high physical inactivity. 
Tabel 1. The General Charachteristics and Physical Inactivity of the Respondents

\begin{tabular}{ccccc}
\hline Variables & \multicolumn{2}{c}{ Case } & \multicolumn{2}{c}{ Control } \\
\cline { 2 - 5 } & $\mathbf{N}$ & $\mathbf{\%}$ & $\mathbf{n}$ & $\mathbf{\%}$ \\
\hline Sex & & & & \\
- Female & 16 & 51.6 & 15 & 48.4 \\
- Male & 8 & 57.1 & 6 & 42.9 \\
Age & & & & \\
- 15 years old & 13 & 50.0 & 13 & 50.0 \\
- 16 years old & 11 & 57.9 & 8 & 42.1 \\
- 17 years old & 11 & 57.9 & 8 & 42.1 \\
Physical Inactivity & & & & \\
- High & 31 & 77.5 & 15 & 37.5 \\
- Low & 9 & 22.5 & 25 & 62.5 \\
\hline
\end{tabular}

Table 2 shows that physical inactivity was significantly associated with overnutrition in adolescent $(\mathrm{p}<0.05 ; \mathrm{OR}=4.2 ; 95 \% \mathrm{CI}: 1.5837-11.1385)$. The results of the Mc Nemar test showed that adolescents who are high physically inactivity are at 4.2 times the risk of being overnutrition compared to adolescents who are low physically inactivity.

Table 2. Association between Physical Inactivity and Overnutrition in Adolescent*

\begin{tabular}{ccccccc}
\hline \multirow{3}{*}{ Case } & & \multicolumn{3}{c}{ Control } & & \\
\cline { 2 - 4 } & Phisycal & \multicolumn{2}{c}{ Phisycal Inactivity } & OR (95\% CI) & p-value** \\
\cline { 2 - 4 } & Inactivity & High & Low & & \\
\cline { 2 - 4 } & High & 10 & 21 & $4.2(1.5837-11.1385)$ & 0.001 \\
\hline & Low & 5 & 4 & & \\
\hline
\end{tabular}

* McNemar test

** significant $(\mathrm{p}<0.05)$

\section{Discussion}

This study shows the prevalence of the high physical inactivity in the case group more than the control group (see Table 1). In line, the current study showed that students who are less physical activity did overweight and obesity [6]. Overweight and obesity in adolescence whose physical inactivity is due to the number of calories expenditure less than the calories obtained from food consumed so that the potential to cause accumulation of excess fat in the body [7].

This study shows that physical inactivity had significant association toward overnutrition in adolescence (see Table 2). The result is consistent with Aryeetey et al study, declares that physical inactivity has an association with overnutrition [8].

Physical inactivity in adolecence resulting in sedentary behavior life style. Sedentary lifestyle is grouped into five categories based display, education, travel, cultural activities and social events [5]. This study results showed that all of the dimensions of a sedentary lifestyle have a significant association with overnutrition. The result is supported by recent some studies [9-12], declares that physical inactivity have a risk to become overnutrition in adolescent. Knowledge of the physical inactivity that one of the play important roles in adolescence overnutrition development can help us create prevention strategies, although physical activity guidelines have been ready. 


\section{Conclusion}

Overnutrition in adolescence could be caused by the physical inactivity. Physical inactivity are important contributing factors to become overnutrition in adolescence. Prevention of physical inactivity is important in the reduction overnutrition. Schools can identified as an ideal environment for interventions as adolescents spend much of their time and offered the instruction and knowledge required to maintain physical activity habits.

\section{Refernces}

[1] WHO. Obesity and Overweight 2017.

[2] WHO. Childhood overweight and obesity. 2017.

[3] Ministry of Health (Kementrian Kesehatan RI). Basic Health Research - RISKESDAS 2013. Jakarta: Badan Litbangkes; 2013

[4] WHO. Obesity: preventing and managing the global epidemic (WHO Technical Report Series 894). Geneva: WHO; 2000 .

[5] Hardy LL, Booth ML, Okely AD. The reliability of the Adolescent Sedentary Activity Questionnaire (ASAQ). Preventive Medicine. 2007:45:71-4

[6] Li C, Yuan Z, Clements-Nolle K, Fu Y, Deadmond M, Yang W. Physical activity and overweight/obesity among academic stressed adolescents. Biostatistics Epidemiol Int J. 2018;I:40-6

[7] Giroux V, Saidj S, Simon C, Laville M, Segrestin B, Mathieu M-E. Physical activity, energy expenditure and sedentary parameters in overfeeding studies - a systematic review. BMC Public Health. 2018;18:903.

[8] Aryeetey R, Lartey A, Marquis GS, Nti H, Colecraft E, Brown P. Prevalence and predictors of overweight and obesity among school-aged children in urban Ghana. BMC Obesity. 2017;4:38.

[9] Mustelin L, Silventoinen K, Pietilainen K, Rissanen A, Kaprio J. Physical activity reduces the influence of genetic effects on BMI and waist circumference: a study in young adult twins. International journal of obesity (2005) 2009;33:29-36.

[10] Lowry R, Wechsler H, Galuska DA, Fulton JE, Kann L. Television viewing and its associations with overweight, sedentary lifestyle, and insufficient consumption of fruits and vegetables among US high school students: differences by race, ethnicity, and gender. The Journal of school health. 2002;72:413-21.

[11] Mushtaq MU, Gull S, Mushtaq K, Shahid U, Shad MA, Akram J. Dietary behaviors, physical activity and sedentary lifestyle associated with overweight and obesity, and their socio-demographic correlates, among Pakistani primary school children. The international journal of behavioral nutrition and physical activity. 2011;8:130.

[12] Zhang G, Wu L, Zhou L, Lu W, Mao C. Television watching and risk of childhood obesity: a meta-analysis. European journal of public health. 2016;26:13-8. 